\title{
A synergistic approach to anion antiport
}

\author{
Stephen J. Moore, ${ }^{a}$ Matthew G. Fisher, ${ }^{a}$ Masafumi Yano ${ }^{a, b}$ Christine C. Tong ${ }^{a, c}$ and Philip A. Gale ${ }^{a, *}$ \\ Received (in $X X X, X X X)$ Xth $X X X X X X X X X 20 X X$, Accepted Xth $X X X X X X X X X 20 X X$ \\ DOI: $10.1039 / \mathbf{b 0 0 0 0 0 0 x}$
}

\begin{abstract}
${ }_{5}$ A synergistic approach to $\mathrm{Cl}^{-} / \mathrm{HCO}_{3}^{-}$antiport has been demonstrated in POPC lipid bilayers using an ion selective electrode assay showing that, when using combinations of carriers each optimised for a particular component of the transport process, enhanced rates of transport are observed.
\end{abstract}

10 Bicarbonate transporter proteins are essential for metabolism and the excetion of bicarbonate, whole-body $\mathrm{pH}$ regulation and the control of cell volume that chiefly operate by $\mathrm{Cl}^{-} / \mathrm{HCO}_{3}^{-}$ exchange (sodium dependent or independent) and $\mathrm{Na}^{+} / \mathrm{HCO}_{3}{ }^{-}$ cotransport. ${ }^{1}$ Dysregulation of chloride transport in the epithelia 15 of cystic fibrosis (CF) patients has long been known, however dysregulation of bicarbonate transport has also been linked to disease states including cystic fibrosis, infertility and heart disease. ${ }^{2}$ In particular Quinton has recently hypothesised that the defect in bicarbonate transport in CF may be the basis for 20 pathogenic mucus production. ${ }^{3}$

Hence the development of transporters for bicarbonate and chloride is currently of intense interest both for use as tools for the study of membrane transport processes in biological systems and also as potential future treatments for these diseases. ${ }^{4}$ For 25 example, a range of molecules have been identified as efficient $\mathrm{Cl}^{-} / \mathrm{HCO}_{3}^{-}$antiporters in lipid vesicles including; tripodal tristhioureas based upon the tris(2-aminoethyl)amine scaffold, ${ }^{5}$ the natural product prodigiosin and structurally related isophthalamides, ${ }^{6}$ structurally simple thioureas bearing an iso${ }_{30}$ pentyl groups, ${ }^{7}$ urea appended decalins ${ }^{8}$ and the sphingolipid ceramide. $^{9}$

Transport processes in cells do not function independently from one another but rather are coupled together. We therefore thought it would be interesting to begin to combine discrete 35 molecular carriers with contrasting transport properties to produce transport systems that function synergistically. In the simplest case, by considering an electroneutral transport process as two coupled uniport steps, two carriers could be used synergistically, with each receptor facilitating one of the uniport 40 pathways in a so-called "dual host" system. The potassium ionophore valinomycin has been used in conjunction with protonophoric compounds, such as chlorophenols, to achieve synergistic $\mathrm{K}^{+} / \mathrm{H}^{+}$transport. ${ }^{10}$ Similarly, $\mathrm{K}^{+} / \mathrm{Cl}^{-}$transport can be facilitated by a combination of valinomycin and naturally ${ }^{11}$ or ${ }_{45}$ synthetically ${ }^{12}$ derived chloride channels. We recently reported a dual host system for the co-transport of $\mathrm{K}^{+} / \mathrm{Cl}^{-}$comprising valinomycin and triazole strapped calixpyrroles $\mathbf{1}$ and $2 .{ }^{13}$ The synergistic action of the two compounds was demonstrated in a series of fluorescence assays using the chloride sensitive dye so lucigenin, encapsulated within 1-palmitoyl-2-oleoyl-sn-glycero3-phosphocholine (POPC) vesicles.

We wished to explore whether we could use a combination of anion receptors to enhance the exchange of $\mathrm{Cl}^{-}$and $\mathrm{HCO}_{3}{ }^{-}$across a lipid bilayer in the first example of a dual host approach to 55 anion-anion antiport. By combining a receptor optimised for chloride transport with one optimised for bicarbonate transport then we hoped to see the combination of receptors resulting in faster chloride/bicarbonate antiport than sum of the transport resulting from each of the receptors acting alone.

60 To achieve this we selected a set of compounds capable of chloride uniport only and studied the effect of these carriers on chloride/bicarbonate antiport mediated by a second set of compounds. Triazole strapped calixpyrroles $\mathbf{1}$ and $\mathbf{2}$ have been shown to facilitate both $\mathrm{M}^{+} / \mathrm{Cl}^{-}$symport and $\mathrm{Cl}^{-} / \mathrm{NO}_{3}{ }^{-}$antiport in ${ }_{65}$ model systems ${ }^{14}$ whilst meso-octamethylcalix[4]pyrrole (3) has only been found to transport chloride as a caesium chloride ion pair. ${ }^{15}$ Thus compounds $\mathbf{1}$ and $\mathbf{2}$ are capable of facilitiating chloride uniport whilst compound $\mathbf{3}$ cannot. ${ }^{13}$ However, neither compounds 1 or 2 are capable of facilitating $\mathrm{Cl}^{-} / \mathrm{HCO}_{3}{ }^{-}$antiport to 70 a significant degree. In contradistion to these results, thiourea compounds 4 and 5 have been shown to facilitate both $\mathrm{Cl}^{-} / \mathrm{NO}_{3}{ }^{-}$ and $\mathrm{Cl}^{-} / \mathrm{HCO}_{3}{ }^{-}$antiport. ${ }^{7}$ In fact, compound $\mathbf{5}$ shows transport activity in POPC lipid vesicles at concentrations as low as 0.004 mol\% (with respect to lipid). Proton NMR titrations in DMSO$75 d_{\delta} 0.5 \%$ water reveal that these compounds show selectivity for

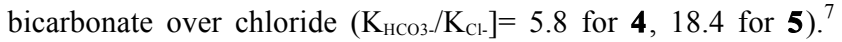

We then studied the effect of calixpyrroles 1-3 on $\mathrm{Cl}^{-} / \mathrm{HCO}_{3}{ }^{-}$ antiport processes mediated by $\mathbf{4}$ and $\mathbf{5}$. To achieve this, unilamellar POPC vesicles were prepared containing $489 \mathrm{mM}$ 80 sodium chloride solution buffered to $\mathrm{pH} 7.2$ with $20 \mathrm{mM}$ sodium phosphate salts. The vesicles were dialysed to remove unencapsulated chloride to form a stock solution of vesicles loaded with chloride. The vesicles were then suspended in 167 $\mathrm{mM}$ sodium sulfate buffered to $\mathrm{pH} 7.2$ with $20 \mathrm{mM}$ sodium ${ }_{85}$ phosphate salts. The carriers were added individually and in combination as solutions in DMSO at $2 \mathrm{~mol} \%$ (with respect to lipid) loadings, with the exception of compound 4 which was added at $0.03 \mathrm{~mol} \%$ (with respect to lipid) due to its inherently higher transport activity. The system was allowed to equilibrate ${ }_{90}$ for $60 \mathrm{~s}$ after which time a pulse of $\mathrm{NaHCO}_{3}$ was added (such that the concentration of the salt in the extravesicular solution was $40 \mathrm{mM}$ ). Chloride efflux was monitored using an ion selective electrode (Accumet). After $660 \mathrm{~s}$ the vesicles were lysed 
with detergent (octaethylene glycol monododecyl ether) to allow determination of $100 \%$ chloride efflux. Control experiments were performed without the bicarbonate pulse to examine the possibility of $\mathrm{H}^{+} / \mathrm{Cl}^{-}$co-transport (see ESI).
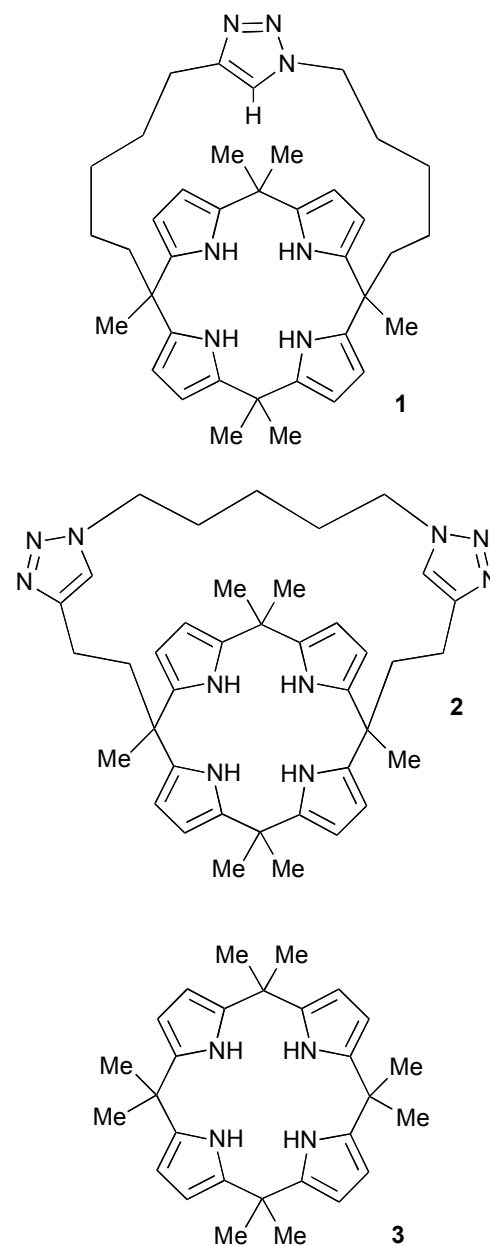<smiles>CCCCNC(=S)NCCC(C)C</smiles><smiles>CC(C)CCNC(=S)Nc1cccc2cc[nH]c12</smiles>

The results of the bicarbonate pulse experiment with thiourea ${ }_{10} 4$ and calixpyrrole analogues 1, 2 and 3 are shown in Figures 13. In each case the results show the effect of adding the thiourea compound alone, the calixpyrrole alone and then the effect of adding the two compounds simultaneously. In addition the corrected "sum" of the change in chloride concentration of 15 adding the thiourea and the calixpyrrole seperately is shown.

An enhancement in $\mathrm{Cl}^{-} / \mathrm{HCO}_{3}^{-}$transport is observed when compounds $\mathbf{1}$ or $\mathbf{2}$ are added with thiourea $\mathbf{4}$ (compared to the individual 'sum' of chloride efflux derived from adding the compounds seperately) demonstrating a synergistic effect (see
${ }_{20}$ Figures 1 and 2). This supports the hypothesis that these compounds can participate in a dual host system for the transmembrane transport of chloride and bicarbonate via two coupled uniport processes. The potential transport processes in this system are shown schematically in Scheme 1. The addition 25 of compounds $\mathbf{1}$ and $\mathbf{2}$ provides an additional chloride uniport pathway. In order to maintain charge neutrality for every chloride anion transported out of the vesicle a bicarbonate anion must be transported in. Hence the enhanced rate of chloride transport observed when compounds $\mathbf{1}$ or $\mathbf{2}$ are added with 30 compound $\mathbf{4}$ is due to effectively enhanced membrane permeability for chloride (due to the mechanism shown in Scheme 1a) in the presence of the calixpyrroles which allows compound 4 to transport bicarbonate at a faster rate (Scheme 1c).

In agreement with our previous $\mathrm{K}^{+} / \mathrm{Cl}^{-}$dual host study, ${ }^{13}$ no 35 significant enhancement in transport was observed when mesooctamethylcalix[4]pyrrole $\mathbf{3}$ was added in conjunction with thioureas $\mathbf{4}$ or $\mathbf{5}$ (see Figure 3). Control experiments demonstrated that the observed synergy was not a consequence of dual host $\mathrm{H}^{+} / \mathrm{Cl}^{-}$co-transport. ${ }^{16}$

40 Similar results are observed in experiments with thiourea $\mathbf{5}$ and calixpyrroles $\mathbf{1}, \mathbf{2}$ and $\mathbf{3}$ (see ESI)

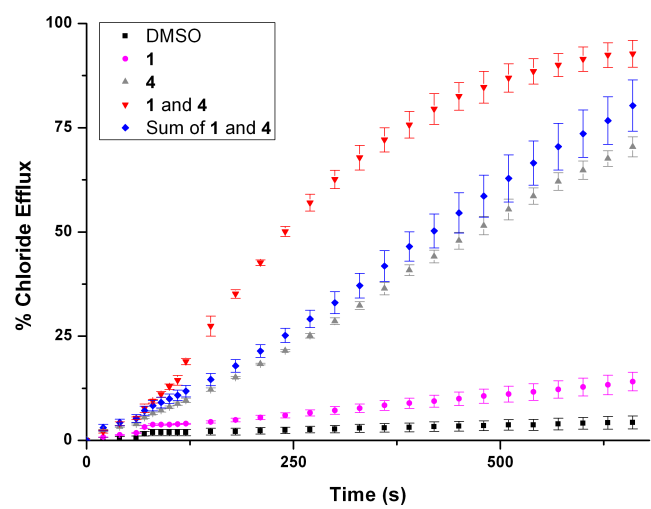

Figure 1 Chloride efflux from unilamellar POPC vesicles containing $489 \mathrm{mM}$ sodium chloride, buffered to $\mathrm{pH} 7.2$ with $20 \mathrm{mM}$ sodium phosphate salts and suspended in $167 \mathrm{mM}$ sodium sulfate, buffered to $\mathrm{pH}$ 7.2 with $20 \mathrm{mM}$ sodium phosphate salts, upon addition of DMSO solutions of $1(2 \mathrm{~mol} \%), \mathbf{4}(2 \mathrm{~mol} \%)$ and both $1(2 \mathrm{~mol} \%)$ and $4(2$ $\mathrm{mol} \%)$. The sum of $\mathbf{1}(2 \mathrm{~mol} \%)$ and $\mathbf{4}(2 \mathrm{~mol} \%)$ is shown for comparison. 50 A sodium bicarbonate pulse was added at $\mathrm{t}=60 \mathrm{~s}$ such that the external bicarbonate concentration was $40 \mathrm{mM}$. Each point represents an average of three trials. 


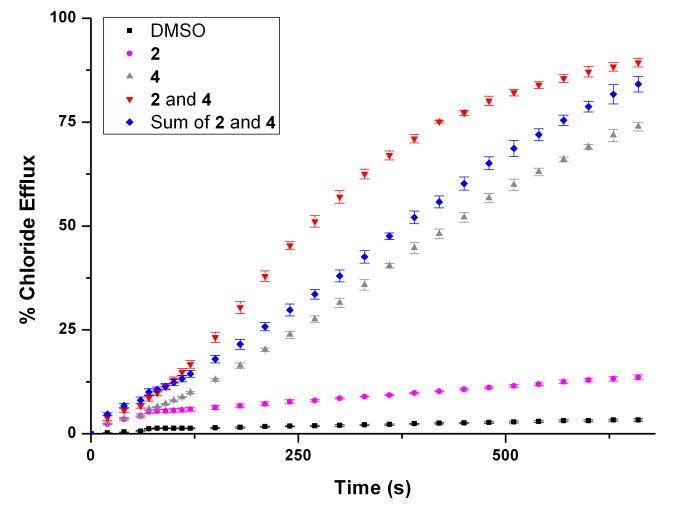

Figure 2 Chloride efflux from unilamellar POPC vesicles containing $489 \mathrm{mM}$ sodium chloride, buffered to $\mathrm{pH} 7.2$ with $20 \mathrm{mM}$ sodium 5 phosphate salts and suspended in $167 \mathrm{mM}$ sodium sulfate, buffered to $\mathrm{pH}$ 7.2 with $20 \mathrm{mM}$ sodium phosphate salts, upon addition of DMSO solutions of $2(2 \mathrm{~mol} \%), 4(2 \mathrm{~mol} \%)$ and both $2(2 \mathrm{~mol} \%)$ and 4 (2 $\mathrm{mol} \%)$. The sum of $2(2 \mathrm{~mol} \%)$ and $4(2 \mathrm{~mol} \%)$ is shown for comparison A sodium bicarbonate pulse was added at $\mathrm{t}=60 \mathrm{~s}$ such that the external 10 bicarbonate concentration was $40 \mathrm{mM}$. Each point represents an average of three trials.

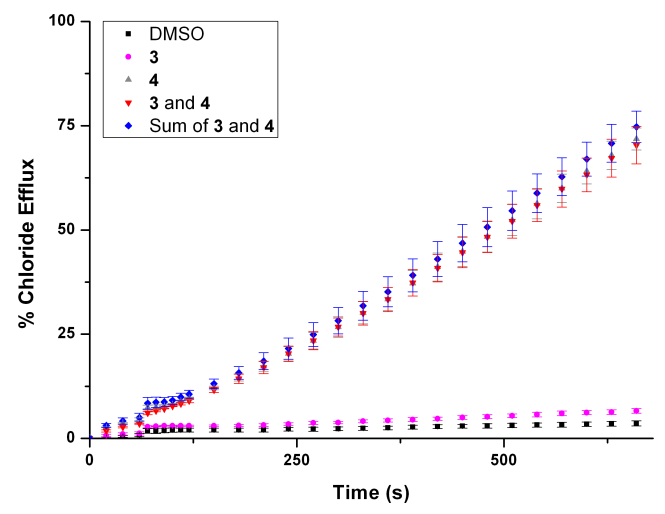

Figure 3 Chloride efflux from unilamellar POPC vesicles containing $489 \mathrm{mM}$ sodium chloride, buffered to $\mathrm{pH} 7.2$ with $20 \mathrm{mM}$ sodium phosphate salts and suspended in $167 \mathrm{mM}$ sodium sulfate, buffered to $\mathrm{pH}$ 7.2 with $20 \mathrm{mM}$ sodium phosphate salts, upon addition of DMSO solutions of 3 ( $2 \mathrm{~mol} \%), 4(2 \mathrm{~mol} \%)$ and both $3(2 \mathrm{~mol} \%)$ and 4 (2 mol\%). The sum of $3(2 \mathrm{~mol} \%)$ and $4(2 \mathrm{~mol} \%)$ is shown for comparison.

20 A sodium bicarbonate pulse was added at $\mathrm{t}=60 \mathrm{~s}$ such that the external bicarbonate concentration was $40 \mathrm{mM}$. Each point represents an average of three trials.

\section{Conclusions}

We have shown that the addition of receptors optimised for ${ }_{25}$ chloride transport with those optimised for bicarbonate transport can result in enhanced rates of $\mathrm{Cl}^{-} / \mathrm{HCO}_{3}{ }^{-}$antiport over each receptor functioning alone. Not only does this suggest that with careful selection of the transport components it may be possible to expand this methodology to a range of other transport 30 processes, including $\mathrm{H}^{+} / \mathrm{Cl}^{-}$co-transport but that the use of this type of small molecule carrier in a cell rather than in a model vesicle system may result in enhanced rates of tranport due to coupling between the transport mediated by the synthetic carrier and other transport processes present in the cell membrane.

Acknowledgements

PAG thanks the EPSRC and the NSF for funding. MY thanks the Kansai University's Overseas Reasearch Program (2009) for support.

\section{${ }_{40}$ Notes and references}

${ }^{a}$ School of Chemistry, University of Southampton, Southampton, SO17 1BJ, UK ; E-mail: philip.gale@soton.ac.uk; Fax: +44(0)2380596805; Tel: +44(0)2380593332

${ }^{b}$ Faculty of Chemistry, Material and Bioengineering, Kansai University 45 3-3-35 Yamate-cho, Suita 565-8680, Japan

${ }^{c}$ Present address: Department of Chemistry, Regis University, 3333 Regis Blvd, Denver, Colorado, USA 80221-1099

$\uparrow$ Electronic Supplementary Information (ESI) available: details of membrane transport studies and graphs showing change in internal 50 chloride concentration for compound 5. See DOI: 10.1039/b000000x/

1 J. R. Casey, Biochem. Cell. Biol., 2006, 84, 930-939.

2 J. Y. Choi, D. Muallem, K. Kiselyov, M. G. Lee, P. J. Thomas and S. Muallem, Nature, 2001, 410,94-97; for a comprehensive review on 55 the role of bicarbonate transport in disease see E. Cordat and J. R. Casey, Biochem J., 2009, 417, 423-439;

3. P.M. Quinton, Am. J. Physiol. Lung Cell Mol. Physiol., 2010, 298, L13-L14; P.M. Quinton, Lancet, 2008, 372, 415-417.

4 A. P. Davis, D. N. Sheppard and B. D. Smith, Chem. Soc. Rev., 2007,

60 36, 348-357; G. W. Gokel and N. Barkey, New J. Chem., 2009, 33, 947-977; J. Mareda and S. Matile, Chem. Eur. J., 2009, 15, 28-37; J. T. Davis, O. Okunola and R. Quesada, Chem. Soc. Rev., 2010, 39, 3843-3862; P. A. Gale, Acc. Chem. Res., 2011, 44, 216-226.

5 N. Busschaert, P. A. Gale, C. J. E. Haynes, S. J. Moore, C. C. Tong,

65 J. T. Davis and W. A. Harrell Jr., Chem. Commun., 2010, 46, 62526254.

6 J. T. Davis, P. A. Gale, O. A. Okunola, P. Prados, J. C. IglesiasSanchez, T. Torroba and R. Quesada, Nature Chem., 2009, 1, 138144.

707 N. J. Andrews, C. J. E. Haynes, M. E. Light, S. J. Moore, C. C. Tong, J. T. Davis, W. A. Harrell Jr. and P. A. Gale, Chem. Sci., 2011, 2, 256-260.

8 S. Hussain, P. R. Brotherhood, L. W. Judd and A. P. Davis, J. Am. Chem. Soc., 2011, DOI: 10.1021/ja1076102.

759 W. A. Harrell Jr., M. L. Bergmeyer, P. Y. Zavalij and J. T. Davis, Chem. Commun., 2010, 46, 3950-3952.

10 G. Krishnamoorthy, FEBS Lett., 1988, 232, 199-203; V. N. Orlov, Y. N. Antonenko, A. A. Bulychev and L. S. Yaguzhinsky, FEBS Lett., 1994, 345, 104-106; B. S. Prabhananda and M. H. Kombrabail,

80 J. Phys. Chem. B., 1998, 102, 8619-8628; J. Hudson, A. E. G. Cass and B. S. Prabhananda, Phy. Chem. Chem. Phys., 2002, 4, 27022707.

11 B. M. Tulk, P. H. Schlesinger, S. A. Kapadia and J. C. Edwards, J. Biol. Chem., 2000, 275, 26986-26993.

8512 P. H. Schlesinger, R. Ferdani, J. Liu, J. Pajewski, M. Saito, H. Shabany and G. W. Gokel, J. Am. Chem. Soc., 2002, 124, 1848-1849

13 S. J. Moore, M. G. Fisher, M. Yano, C. C. Tong and P. A. Gale, Chem. Commun., 2011, 47, 689-691.

14 M. G. Fisher, P. A. Gale, J. R. Hiscock, M. B. Hursthouse, M. E. Light, F. P. Schmidtchen and C. C. Tong, Chem. Commun., 2009, 3017-3019; M. Yano, C. C. Tong, M. E. Light, F. P. Schmidtchen and P. A. Gale, Org. Biomol. Chem., 2010, 8, 4356-4363.

15 C. C. Tong, R. Quesada, J. L. Sessler and P. A. Gale, Chem. Commun., 2008, 6321-6323.

9516 V. Sidorov, F. W. Kotch, J. L. Kuebler, Y. Lam and J. T. Davis, J. Am. Chem. Soc., 2003, 125, 2840-2841; P. A. Gale, M. E. Light, B. McNally, K. Navakhun, K. E. Sliwinski and B. D. Smith, Chem. Commun., 2005, 3773-3775; P. A. Gale, J. Garric, M. E. Light, B. A. McNally and B. D. Smith, Chem. Commun., 2007, 1736-1738; K. J. 
Winstanley, S. J. Allen and D. K. Smith, Chem. Commun., 2009, 4299-4301.

a)

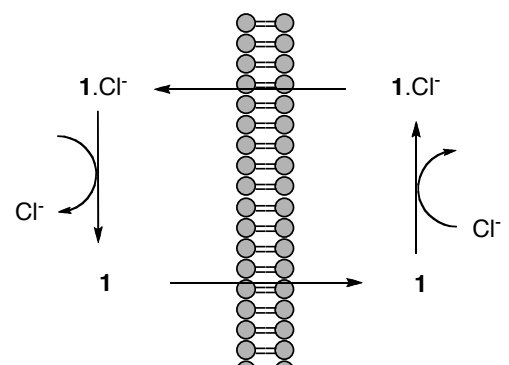

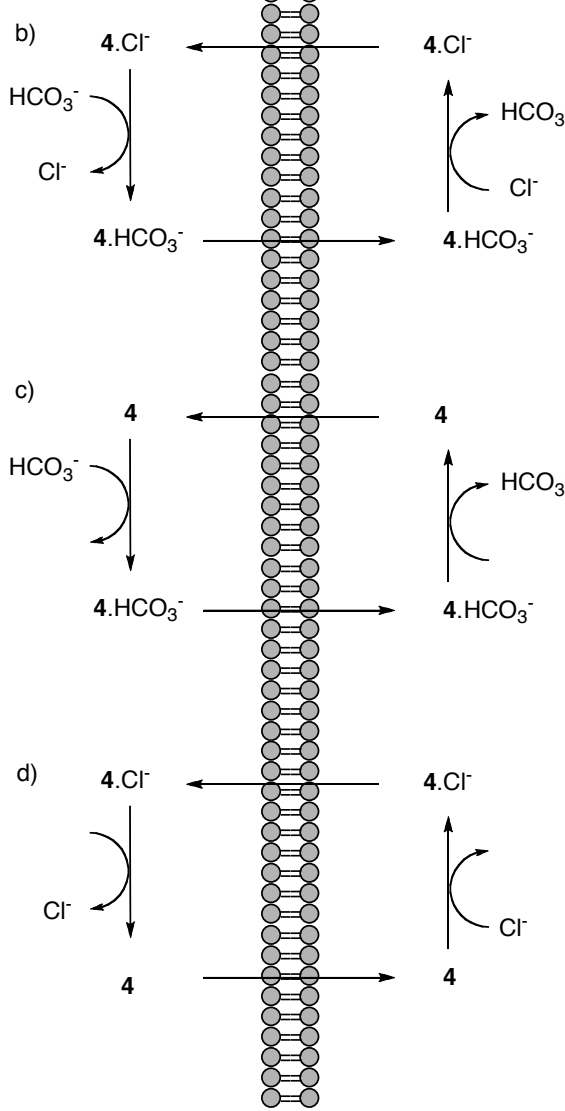

Scheme 1 The chloride and bicarbonate transport processes occurring in the 1-4 transport system: a) chloride uniport by compound $1 ; b$ ) chloride/bicarbonate antiport by compound $\mathbf{4}$ which could be regarded as

two coupled uniport processes for bicarbonate (c) and chloride (d).

Chloride/bicarbonate antiport can also be achieved by coupling processes a) and c). 